\title{
Modern Architecture in Green Design
}

\author{
$\mathrm{Xu}$ Tan
}

\begin{abstract}
While highly regarding the world-wide environmental issues, the modern architecture has entered a place of technology forming a sustainable architecture, also called green architecture, applying energy and ecological techniques in designs of the buildings. In this work, we describe several typical modern green buildings. These designs of green architecture, or ecological architecture, are to make human actions and decisions in daily life do not inhibit the opportunities of our next generations. The design of shape for green building is presented in this work. The spatial arrangement of a building should consider not only the functionalities of facilities but also the structural factors, such as shape coefficient, level height, internal and external physics. The results of our model considering three major energy consumptions, including electricity, heating and cooling present the relationship between building shape and energy consumption. Also, a green building firstly should have a well-arranged space with the lowest energy consumption, considering electricity, heating and cooling system. One of the best methods is to utilize the natural resources, including wind, sunlight, water and earth, and environmental conditions to reduce its energy consumption. In this work, a solar system and wastewater treatment system have been introduced and designed in this work for green purpose.
\end{abstract}

Keywords - Modern architecture, green buildings, sustainable, design.

\section{INTRODUCTION}

In the year 1932, Philip Johnson and Henry-Russell Hitchcock presented an international-styled architecture with similar purpose and design in the International Exhibition of Modern Architecture held at the Museum of Modern Art (New York, USA). This was one of the most important turning points, since when the modern architecture had been admitted and spread universally. As time goes by with a development of society, there have been several styles of modern architecture developed, such as high-tech, postmodern, neo-modern, neo-futuristic and the integration of urbanism and classical designs. Among these designs, some works and architects have to be addressed as revolution points of modern architecture, including the City of Wine Complex, Northern Spain designed by Frank Gehry, the Fallingwater Residence in Mill Run, Pennsylvania designed by Frank Lloyd Wright, the Entrance to the Le Grand Louvre, Paris designed by Ieoh Ming Pei, the Crystal Cathedral in California designed by Philip Johnson, the Burj Al Arab in

Faculty of Design, Architecture and Building, University of Technology Sydney, Sydney 2007, NSW, Australia
Dubai designed by Tom Wright, the Shard as Europe's tallest skyscraper in London designed by Renzo Piano, and so forth.

While highly regarding the world-wide environmental issues, the modern architecture has entered a place of technology forming a sustainable architecture, also called green architecture, applying energy and ecological techniques in designs of the buildings [1, 2]. Typically hazardous gas pollution in cities requires a good design of modern building to minimize health threat using air fluid mechanism[3]. Thus green design is one of the main factors should be considered in modern architecture, as Cook and Golton said: "the designation 'green' is extremely wide ranging, encompassing many viewpoints and open to broad interpretation"[4]. Also for health care and educations purpose that environmental protection and energy saving are important lessons that need to be addressed in people's daily life, modern architecture in green design has been an emerging topic in recent years [5, $6]$.

\section{DESIGN OF GREEN BUILDINGS}

\section{A. Typical Modern Works}

The design of green architecture, or ecological architecture, is to make human actions and decisions in daily life do not inhibit the opportunities of our next generations. Universally there has been large consumption of energy, electricity, water and materials for buildings, where a great number of people live in. The buildings have a great potential to reduce emissions for sustainable development of society. Nowadays, there have been some good designs for green purpose, fully assisted with energy and ecological techniques. Figure 1a shows the design of the BRB embraces the moderate climate of Ireland. This building has utilized the normal wind as the energy resource that $45 \%$ of this building can work without other methods of ventilation, due to a its structural design along with the environmental conditions (typically the wind[7]). Apart from the wind, for cities near the ocean or a river, water is able to be used as a supporting natural resource, such as the Exploratorium at Pier 15 in San Francisco, USA (Figure 1b). As near the ocean, this project has used its roof which is 800 feet long for photovoltaic application. The water from the ocean is used in coolingheating system. The building is now a non-energy-import place and a model of green architecture for good reputation. Similar to utilize the solar energy, the J. Craig Venter Institute in California, USA has also used the LEED- 
Platinum system for photovoltaic application (Figure 1c). It is aN about 45,000 square feet place generating energy for daily consumption in offices and labs. Besides, it contains some other sustainable techniques in the green design including electronic performance, water use, and building materials. As a typical and beautiful green building, shown in Figure 1d, known as the forest in building in Lausanne, Switzerland, the project has utilized visible green plants as part of the architecture for art purpose, in addition to the sustainable designs including wind ventilation, heating system and energy savings. Similarly, hanging gardens of One Central Park, Sydney is another sample for the art purpose with green architecture.

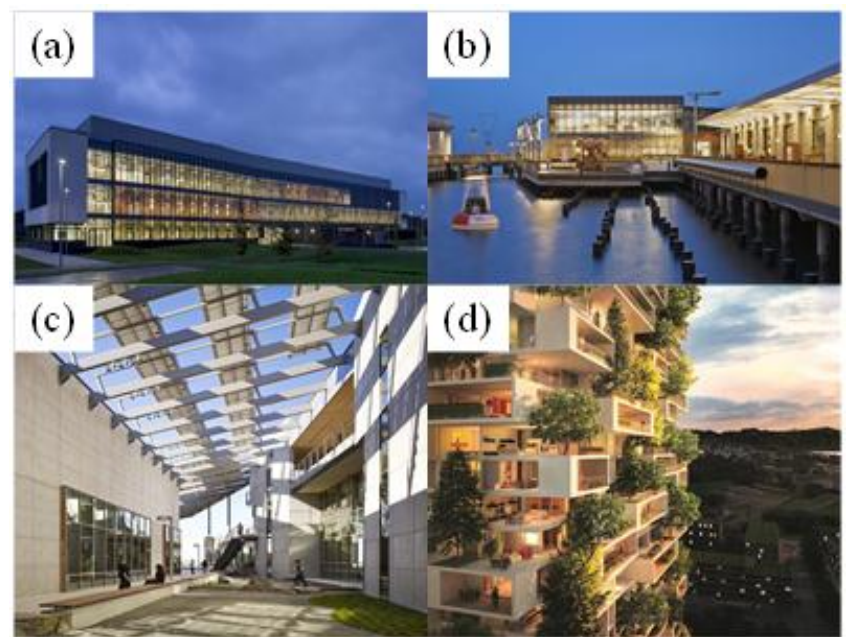

Fig. 1: Typical green designs. a: the BRB embraces the moderate climate of Ireland; b: as the Exploratorium at Pier 15 in San Francisco; c: the J. Craig Venter Institute in California, USA; d: the forest in building in Lausanne, Switzerland

\section{B. Design of Green Buildings}

An overall factor for green design is spatial arrangement. A green building firstly should have a well-arranged space with the lowest energy consumption, considering electricity, heating and cooling system. One of the best methods is to utilize the natural resources, including wind, sunlight, water and earth, and environmental conditions to reduce its energy consumption. The spatial arrangement of a building should consider not only the functionalities of facilities but also the structural factors, such as shape coefficient, level height, internal and external physics. For example, a ventilation system should consider the fluid mechanics and aerodynamics from outer environment to the building itself.

In order to design a green building with good spatial arrangement, the first thing always coming in mind is the shape design. In this work we have used the Designbuilder software to calculate the energy consumption for some typical shapes of a $6000 \mathrm{~m}^{2}$ building with different shape coefficient. Results from our model considering three major energy consumptions, including electricity, heating and cooling present the relationship between building shape and energy consumption (Figure 2). The overall energy consumption is shown with different shapes in an increasing order: 1: I-shape $<2$ : oval shape $<3$ : rectangular shape with length/width ratio at $4: 1<4$ : rectangular shape with length/width ratio at $3: 1 \approx$ 5: L-shape < 6: round shape < 7: rectangular shape with length/width ratio at 2:1 $<8$ : rectangular shape with length/width ratio at 1:1 (square) < 9: rectangularambulatory-plane shape < 10: rectangular shape with length/width ratio at 5:1. Interestingly, the order does not follow the rule of shape coefficient for energy consumption. The shape coefficient well-known as the main controller to energy consumption explains how large the surface area contacts with outer environment. Therefore, a building with low shape coefficient generally has a relatively low energy consumption considering the energy transport of electricity, cooling/heating water, air and so on. After a simple calculation, the shape coefficient is shown in the increasing order: 6: round shape (shape coefficient is 0.158 ) < 8 : rectangular shape with length/width ratio at 1:1 (square; shape coefficient is 0.171) $<7$ : rectangular shape with length/width ratio at 2:1 (shape coefficient is 0.178 ) $<10$ : rectangular shape with length/width ratio at 5:1 (shape coefficient is 0.184$)<4$ : rectangular shape with length/width ratio at $3: 1$ (shape coefficient is 0.189 ) $\approx 5$ : L-shape (shape coefficient is 0.189$)<3$ : rectangular shape with length/width ratio at 4:1 (shape coefficient is 0.200 ) < 1 : I-shape (shape coefficient is 0.209$)<9$ : rectangular-ambulatory-plane shape (shape coefficient is 0.256 ) $<2$ : oval shape (shape coefficient is 0.292 ). A shape of green building does not always follow the traditional rule of energy consumption. Many conditions should be considered, such as stairways, elevators, toilets, pipes and electronic lines. For instance, though the round shape (No.6) has a low shape coefficient with also the lowest energy consumption of heating system, the I-shape (No.1) has significant reduced energy consumption of electricity and cooling system. Thus the I-shape design has the lowest value of total energy consumption, considering many conditions again including stairways, elevators, toilets, pipes and electronic lines.

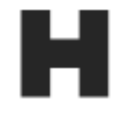

1

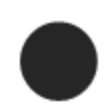

6

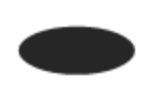

2

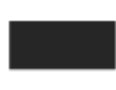

7

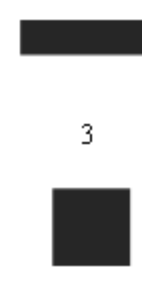

8
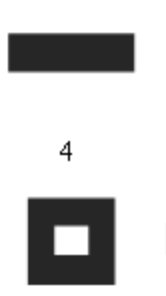

9

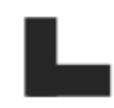

5

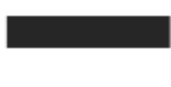

10
Fig. 2: Some typical shapes for design of a green building with the increasing order of energy consumption. 1: I-shape; 2 : oval shape; 3 : rectangular shape with length/width ratio at $4: 1 ; 4$ : rectangular shape with length/width ratio at $3: 1 ; 5$ : L-shape; 6 : round shape; 7 : rectangular shape with length/width ratio at $2: 1 ; 8$ : rectangular shape with length/width ratio at 1:1 (square); 9: rectangular-ambulatoryplane shape; 10: rectangular shape with length/width ratio at 5:1. 


\section{Science and Technologies Used in Green Buildings}

Green buildings have been designed to reduce energy consumption from water, air, electricity extract, process and transport to structural materials that are able to warm the buildings in the winter and cool the buildings in the summer. In order to minimize energy consumption, air leakage via the building barriers between conditioned and unconditioned spaces has been considered in green buildings. Modern windows and enhanced insulation via building barriers has also been used. Besides, solar system of green buildings has been frequently used nowadays to produce electricity, heat water and air. Renewable energy including the solar energy, wind energy, hydro energy, or biological green resources has been widely considered to enhance the environment and health for the buildings.

As the most efficient energy supplier, advanced sunlight equipment such as photovoltaic sunlight system helps to support renewable electrical energy for daily energy consumption. Electricity outputs of a photovoltaic sunlight system largely rely on height, angles, latitude and longitude, weather and climate conditions. Solar system gains different energy even at the same places. Especially, efficiency of common used photovoltaic sunlight system ranges at 4 28\%. A bad efficiency of sunlight system would largely influence its pay-return time of its cost. However, bad efficiencies do not present photovoltaic sunlight systems cannot significantly reduce energy consumption. Actually many people have used photovoltaic sunlight systems in their houses and buildings. Top roof is usually adjusted to a good angle for sunlight adsorption to achieve high energy production using photovoltaic sunlight systems. At northern places, an angle facing the south can increase the energy production for this photovoltaic energy generation system. Whereas much northerner places during the winter, such as Norway, solar resource cannot be utilized. In order to increase the energy production during the winter, a photovoltaic panel must be angled at positive 15 degree of horizontal latitude, while during the summer negative 15 degree should be set. And during other time of a year, difference between the angle of photovoltaic panel and horizontal latitude should be set at 0 degree as usual. Solar systems have also been used to heat water for daily use. Universally, the solar heating system as an efficient method to collect sunlight energy, which is free, with low cost has been used in almost modern residence places. Besides, a well-deigned wind system to produce wind energy has been used in some green buildings. However by considering the ratio of cost to efficiency, small-scaled wind energy system is not suitable for most green buildings since the wind-energy system is expensive while the efficiency of electricity generation is relatively low.

Green system nowadays also can be designed with an additional wastewater treatment system shown in Figure 3. The system can be designed using a traditional sequencing batch reactor (SBR reactor) with the lowest cost among wastewater treatment and processes including filling, mixing, aeration, settling and extraction. This low cost strategy using activated sludge is the most widely used for the treatment of wastewater [8]. In details for a green building in which 1000 people live, a SBR reactor should contains $50 \mathrm{~L}$ of the activated. During a typical operation of wastewater treatment, the filling process takes $30 \mathrm{~min}$ to load daily wastewater generated by cooking, washing and toileting; the mixing process costs 8 hours to mix biomass (the activated sludge) with wastewater and during this period some biodegradation happens to reduce $\mathrm{NH}_{4}{ }^{+}$wastes; the aeration process takes 12 hours as the main biodegradation process to break down most organic components to carbon dioxide and water with high concentration of oxygen involved; the settling process costs 3 hours to separate liquid from solid for post extraction process; the last extraction process takes $30 \mathrm{~min}$ to output the purified wastewater, which may be used as toilet flushing water or for other washing purposes.

In addition, many sustainable materials have been used for green purpose, including recycled materials, advanced materials and functional materials fabricated by nanotechnology[9].

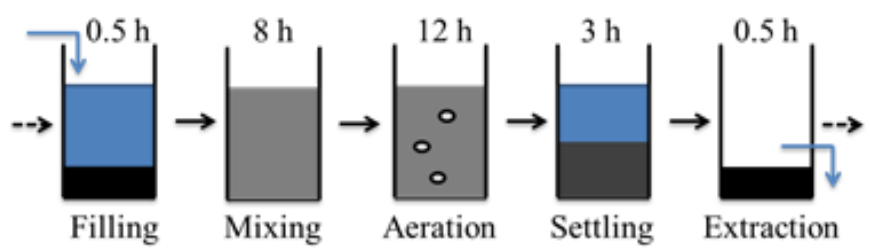

Fig. 3: Schematic of a typical wastewater treatment process

\section{CONCLUSIONS}

While highly regarding the world-wide environmental issues, the modern architecture has entered a place of technology forming a sustainable architecture, also called green architecture, applying energy and ecological techniques in designs of the buildings. Typically hazardous gas pollution in cities requires a good design of modern building to minimize health threat using air fluid mechanism. Green design is one of the main factors should be considered in modern architecture. Also for health care and educations purpose that environmental protection and energy saving are important lessons that need to be addressed in people's daily life, modern architecture in green design has been an emerging topic in recent years.

In this work, we introduce several typical modern green buildings including a: the BRB embraces the moderate climate of Ireland; b: as the Exploratorium at Pier 15 in San Francisco; c: the J. Craig Venter Institute in California, USA; $\mathrm{d}$ : the forest in building in Lausanne, Switzerland. These designs of green architecture, or ecological architecture, are to make human actions and decisions in daily life do not inhibit the opportunities of our next generations. Universally there has been large consumption of energy, electricity, water and materials for buildings, where a great number of people 
live in. The buildings have a great potential to reduce emissions for sustainable development of society.

The design of shape for green building has been presented in this work. The spatial arrangement of a building should consider not only the functionalities of facilities but also the structural factors, such as shape coefficient, level height, internal and external physics. The results of our model considering three major energy consumptions, including electricity, heating and cooling present the relationship between building shape and energy consumption. The overall energy consumption is shown with different shapes in an increasing order: 1: I-shape < 2: oval shape $<3$ : rectangular shape with length/width ratio at 4:1<4: rectangular shape with length/width ratio at $3: 1 \approx 5:$ L-shape $<6$ : round shape $<$ 7: rectangular shape with length/width ratio at 2:1 < 8 : rectangular shape with length/width ratio at $1: 1$ (square) $<9$ : rectangular-ambulatory-plane shape $<10$ : rectangular shape with length/width ratio at 5:1.

Also, a green building firstly should have a well-arranged space with the lowest energy consumption, considering electricity, heating and cooling system. One of the best methods is to utilize the natural resources, including wind, sunlight, water and earth, and environmental conditions to reduce its energy consumption. In this work, a solar system and wastewater treatment system have been introduced and designed in this work for green purpose. Our works, in which we highly recommend the modern architecture in green design, may give researcher and designer an overall idea of how to complement a design of green building.

\section{ACKNOWLEDGMENT}

I am so grateful to Songwen Tan, who works in Faculty of Engineering at the University of Sydney, for all his assistance to the explaining details of science and technology sections in this work.

\section{REFERENCES}

[1] S. Guy and G. Farmer, "Reinterpreting sustainable architecture: The place of technology," Journal Of Architectural Education, vol. 54, pp. 140-148, Feb 2001.

https://doi.org/10.1162/10464880152632451

[2] M. T. Borzacchiello, V. Torrieri, and P. Nijkamp, "An operational information systems architecture for assessing sustainable transportation planning: principles and design," Eval Program Plann, vol. 32, pp. 381-9, Nov 2009. https://doi.org/10.1016/j.evalprogplan.2009.06.012

[3] X. P. Liu, J. L. Niu, K. C. Kwok, J. H. Wang, and B. Z. Li, "Local characteristics of cross-unit contamination around high-rise building due to wind effect: mean concentration and infection risk assessment," J Hazard Mater, vol. 192, pp. 160-7, Aug 152011.

https://doi.org/10.1016/j.jhazmat.2011.04.106

[4] S. J. Cook and B. L. Golton, "Sustainable Development: Concepts and Practice in the Built Environment," Sustainable Construction CIB TG, vol. 16, pp. 677-685, Nov. 19941994.

[5] R. Guenther, "Sustainable architecture for health: a mindset shift," HERD, vol. 2, pp. 3-9, Summer 2009.

https://doi.org/10.1177/193758670900200401
[6] K. T. Cuddeback, "Sustainable healthcare architecture 2nd edition," HERD, vol. 7, pp. 151-4, Winter 2014.

https://doi.org/10.1177/193758671400700211

[7] J. H. Clarke, "The design and location of building inlets and outlets to minimize wind effect and building re-entry of exhaust fumes," Am Ind Hyg Assoc J, vol. 26, pp. 242-8, May-Jun 1965. https://doi.org/10.1080/00028896509342726

[8] M. Gander, B. Jefferson, and S. Judd, "Aerobic MBRs for domestic wastewater treatment: a review with cost considerations," Separation and Purification Technology, vol. 18, pp. 119-130, Mar 62000. https://doi.org/10.1016/S1383-5866(99)00056-8

[9] N. Lubick, "Promising green nanomaterials," Environ Sci Technol, vol. 43, pp. 1247-9, Mar 12009. https://doi.org/10.1021/es900021v 